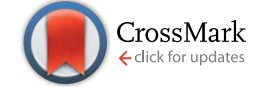

Cite this: RSC Adv., 2017, 7, 1588

Received 21st November 2016 Accepted 20th December 2016

DOI: $10.1039 / c 6 r a 27088 c$

www.rsc.org/advances

\title{
A nitrogen-doped three-dimensional carbon framework for high performance sodium ion batteries $\uparrow$
}

\begin{abstract}
Ying Wang, ${ }^{a}$ Caiyun Wang, ${ }^{c}$ Huinan Guo, ${ }^{b}$ Yijing Wang ${ }^{\star b}$ and Zhenguo Huang ${ }^{\star d}$
A three-dimensional nitrogen-doped carbon framework (NCF) has been synthesized by annealing a zeolitic imidazolate framework (ZIF-67), followed by removing the residual metal ions. The NCF shows a polyhedral outline with strong interconnected hollow nanospheres as its subunits. It is highly porous, with a large surface area of $623 \mathrm{~m}^{2} \mathrm{~g}^{-1}$, and a high nitrogen content of $12.3 \mathrm{wt} \%$. When applied as an anode material for a sodium ion battery, the NCF exhibits an excellent electrochemical performance with a high reversible capacity (327 $\mathrm{mA} \mathrm{h} \mathrm{g}^{-1}$, and stable at $300 \mathrm{~mA} \mathrm{~h} \mathrm{~g}^{-1}$ ), good cycling stability, and excellent rate capability $\left(175 \mathrm{~mA} \mathrm{~h} \mathrm{~g}^{-1}\right.$ at $2000 \mathrm{~mA} \mathrm{~g}^{-1}$ ). The presence of $\mathrm{N}$ in the NCF is believed to provide more active sites for enhancing the electrochemical performance, and provide more defects and nanovoids to trap more $\mathrm{Na}^{+}$ions
\end{abstract}

\section{Introduction}

High energy density storage devices, particularly lithium ion batteries (LIBs), hold the key to the development of portable electronic devices. ${ }^{1-3}$ Their application in electric vehicles and large stationary energy storage, however, has aroused concerns about the supply of lithium. Sodium ion batteries (SIBs) have therefore become the most promising candidate for large-scale energy storage due to the abundance of sodium. ${ }^{4}$ The fundamental working principles of SIBs are similar to those of LIBs. Thus some highly active anode materials in LIBs also display good electrochemical performance in SIBs, such as the conversion-based materials. $^{5-8}$ The search for effective insertion/de-insertion-based anode materials, on the other hand, is still challenging due to the larger radius of $\mathrm{Na}^{+}(0.102$ $\mathrm{nm})$ compared to that of $\mathrm{Li}^{+}(0.076 \mathrm{~nm})$ and its thermodynamic properties. ${ }^{\mathbf{9}, 10}$

Carbon materials show huge potential as anode materials for SIBs owing to their low cost, high chemical stability, and high electrical conductivity. To date, hard carbon has been the most

${ }^{a}$ School of Chemistry and Chemical Engineering, Jiangsu Key Laboratory of Green Synthetic Chemistry for Functional Materials, Jiangsu Normal University, Xuzhou, Jiangsu 221116, China

${ }^{b}$ Collaborative Innovation Centre of Chemical Science and Engineering (Tianjin), Key Laboratory of Advanced Energy Materials Chemistry (MOE), Nankai University, Tianjin 300071, China. E-mail: wangyj@nankai.edu.cn

'Intelligent Polymer Research Institute, ARC Centre of Excellence for Electromaterials Science, University of Wollongong, Wollongong, NSW 2522, Australia

${ }^{d}$ Institute for Superconducting and Electronic Materials, University of Wollongong, Wollongong, NSW 2522, Australia.E-mail: zhenguo@uow.edu.au

† Electronic supplementary information (ESI) available. See DOI: $10.1039 / \mathrm{c} 6 \mathrm{ra} 27088 \mathrm{c}$ investigated anode material, due to its generally larger $d$ spacing. ${ }^{11-15}$ It has shown considerable $\mathrm{Na}^{+}$storage capacity (100-200 $\mathrm{mA} \mathrm{h}^{-1}$ ), but with unsatisfactory cycling stability and rate capability. Improved electrochemical performance could be delivered by using nanostructured carbon materials such as hollow spheres, ${ }^{\mathbf{1 6 , 1 7}}$ nanosheets, ${ }^{18,19}$ and nanofibers. ${ }^{20}$ The porous nature of these materials enables better contact between the electrode and electrolyte, and shortened diffusion paths for $\mathrm{Na}^{+}$ions, and thus improved the electrochemical performance.

The performance of carbon materials can be further optimized by the introduction of heteroatoms (e.g. N, B, P). Heteroatom doped carbon shows higher specific capacities and better cycling stability. ${ }^{21-26}$ Nitrogen has a smaller atomic diameter and higher electronegativity than carbon, and has been considered as a good choice for heteroatom doping. For example, $\mathrm{N}$-doped hollow carbon showed a high capacity of 89.9 $\mathrm{mA} \mathrm{h} \mathrm{g}^{-1}$ at $5 \mathrm{~A} \mathrm{~g}^{-1}$, outperforming the non-doped counterparts. ${ }^{27}$ Tradition fabrication of $\mathrm{N}$-doped carbon materials normally requires the addition of a nitrogen source (ammonia, melamine etc.) or carbonizing polypyrrole, dopamine, or polyacrylonitrile. ${ }^{27-29}$ And the doping level is normally below $\sim 10$ wt $\% .^{30,31}$ Therefore, it would be highly desirable to fabricate nanostructured carbon materials with a higher N-doping level. ${ }^{32,33}$

In this work, we report a highly efficient way to synthesize a three-dimensional (3D) nitrogen-doped carbon framework (NCF) with $12.3 \mathrm{wt} \%$ nitrogen (doping level) derived from a zeolitic imidazolate framework (ZIF-67). The obtained 3D NCF possesses the polyhedral outline of its precursor and consists of hollow nanospheres. Its unique structure facilitates good $\mathrm{Na}^{+}$ storage performance with a high reversible capacity $(327 \mathrm{~mA} \mathrm{~h}$ $\mathrm{g}^{-1}$ ), good cycling stability (86\% capacity retention after 200 
cycles at $\left.100 \mathrm{~mA} \mathrm{~g}^{-1}\right)$, and excellent rate capability $(175 \mathrm{~mA} \mathrm{~h}$ $\mathrm{g}^{-1}$ at a high current density of $2000 \mathrm{~mA} \mathrm{~g}^{-1}$ ).

\section{Experimental}

\subsection{Synthesis of 3D NCF}

2-Dimethylimidazole and $\mathrm{Co}\left(\mathrm{NO}_{3}\right)_{2} \cdot 6 \mathrm{H}_{2} \mathrm{O}$ were purchased from Sigma-Aldrich and used as received. ZIF-67 was synthesized according to a previous report with minor modification. ${ }^{34}$ To obtain the NCF, the ZIF- 67 powders were first heated to $950{ }^{\circ} \mathrm{C}$ (heating rate: $3{ }^{\circ} \mathrm{C} \mathrm{min}{ }^{-1}$, dwell time: $120 \mathrm{~min}$ ) under Ar. After naturally cooling to room temperature, the obtained black powders were treated in $6 \mathrm{M} \mathrm{HCl}$ at $70{ }^{\circ} \mathrm{C}$ for $12 \mathrm{~h}$. This process was repeated three times to completely remove the residual cobalt. The NCF solid powders were collected after centrifugation, rinsed with deionized water, and then dried in an oven at $80^{\circ} \mathrm{C}$.

\subsection{Characterization}

X-ray diffraction (XRD, Rigaku MiniFlexII, $\mathrm{Cu} \mathrm{K} \alpha$ radiation), Xray photoelectron spectroscopy (XPS, VG Scientific ESCALAB 2201XL, Al $\mathrm{K} \alpha \mathrm{X}$-ray radiation), nitrogen sorption isothermal analysis (NOVA 2200e, Quantachrome), and Raman spectroscopy (Jobin Yvon HR800 Raman spectrometer with a $10 \mathrm{~mW}$ helium/neon laser at $632.8 \mathrm{~nm}$ excitation) were used to determine the structure and composition. Element analysis was carried out on an Elementar vario EL CUBE. Scanning electron microscopy (SEM, JEOL JSM7500FA), transmission electron microscopy (TEM), and high-resolution TEM (HR-TEM, JEOL JEM-2010FEF) were used for morphological and structural investigations.

\subsection{Electrochemical measurements}

Standard 2032-type coin cells were assembled to determine the electrochemical performance. The working electrodes were fabricated with $80 \mathrm{wt} \%$ active materials, $10 \mathrm{wt} \%$ acetylene black (Super P), and $10 \mathrm{wt} \%$ sodium carboxymethyl cellulose (CMC). A sodium disc was used as the counter electrode. The electrodes were separated by a glass fiber separator. $1 \mathrm{M} \mathrm{NaClO}_{4}$ in ethylene carbonate and diethyl carbonate with the addition of $5 \%$ fluorinated ethylene carbonate (EC/DEC/FEC) was used as electrolyte. The cells were assembled in an Ar filled glove box with the oxygen and moisture content below $1 \mathrm{ppm}$. Galvanostatic charge-discharge tests were carried out on a battery testing system (Shenzhen NEWARE Battery) over a voltage range of 0.001 to $3.00 \mathrm{~V}$. Electrochemical impedance spectroscopy (EIS) and cyclic voltammetry (CV) measurements were performed on a CHI660E electrochemical workstation.

\section{Results and discussion}

The fabrication procedure for 3D NCF is illustrated in Scheme 1. During the thermal annealing, the organic linkers in ZIF-67 are carbonized into interconnected nitrogen-doped carbon shells, while the $\mathrm{Co}^{2+}$ is reduced to cobalt metal, as previously

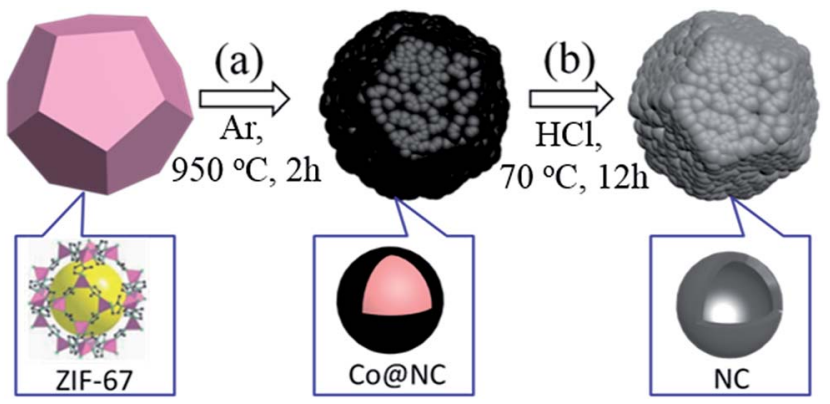

Scheme 1 Schematic illustration of the formation procedure of 3D NCF via calcining ZIF-67 (a), and then etching to remove the Co (b). The figures in the bottom row illustrate the subunit structure of each material.

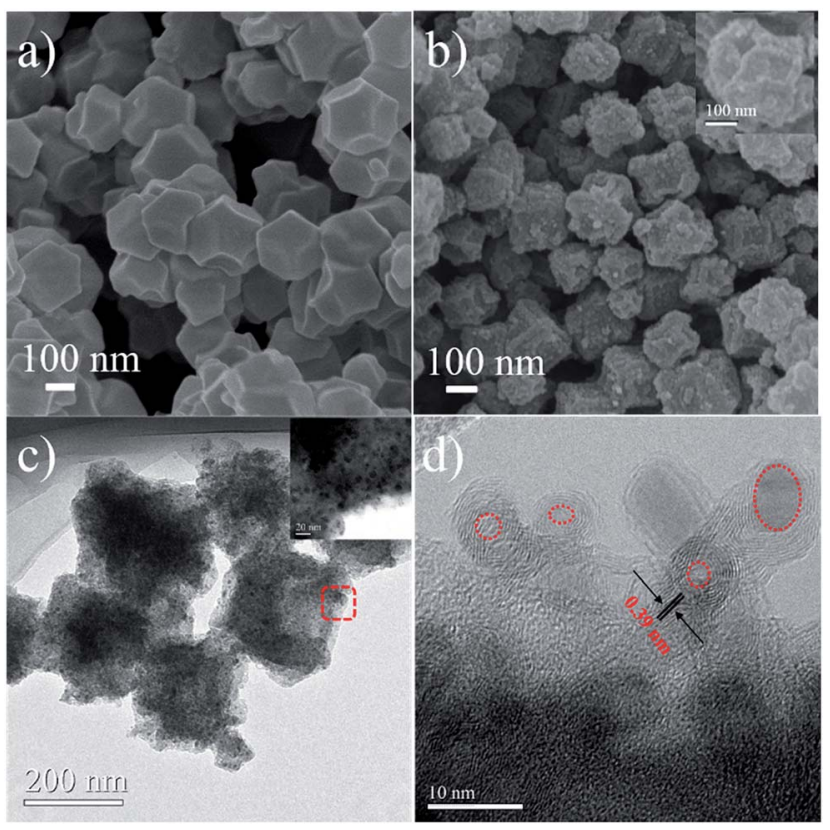

Fig. 1 SEM images of the ZIF-67 precursor (a), and the as-obtained 3D NCF (b), with the inset showing the hollow structure of the polyhedra. TEM (c) and HR-TEM (d) images of the NCF. The inset to (c) is an enlargement of the indicated area, and the red circles in (d) mark the hollow centers of the nanospheres.

reported. ${ }^{5}$ Hydrochloric acid was then used to etch the residual cobalt metal.

The NCF basically inherits the polyhedral structure of ZIF-67, as shown in Fig. 1a. The partially broken polyhedra (inset to Fig. 1b) show their hollow interior. After the calcination the smooth shell of ZIF-67 pyrolyzed into numerous nanoparticles. The TEM images (Fig. 1c) and the HR-TEM image (Fig. 1d) illustrate the hollow nature of the NCF subunit (red circle in Fig. 1c), and the sizes of these hollow nanospheres vary from 3 to $5 \mathrm{~nm}$. The interlayer spacing of NCF is $0.39 \mathrm{~nm}$, which is large enough for sodiation/de-sodiation during the electrochemical process.

The XRD pattern of the NCF (Fig. 2a) shows two strong diffraction peaks of graphite. The C (002) diffraction at $23.0^{\circ}$ 

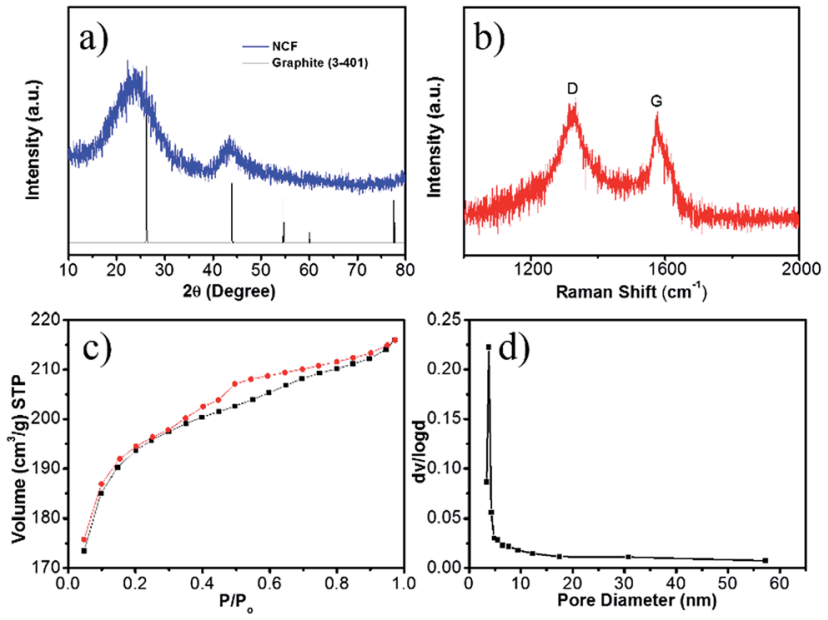

Fig. 2 XRD pattern (a), Raman spectrum (b), nitrogen adsorption isothermal curves (c), and the corresponding pore-size distribution (d) of the 3D NCF.

corresponds to an interlayer spacing of $0.39 \mathrm{~nm}$. Such an enlarged interlayer space has been deemed to be effective for $\mathrm{Na}^{+}$insertion/de-insertion. ${ }^{11,26}$ In its Raman spectrum (Fig. 2b), the $\mathrm{D}$ band (located at $1332 \mathrm{~cm}^{-1}$ ) is associated with structural defects, and the $\mathrm{G}\left(1590 \mathrm{~cm}^{-1}\right)$ band is due to $\mathrm{sp}^{2}$ carbon. The intensity ratio of the $\mathrm{D}$ band to the $\mathrm{G}$ band $\left(I_{\mathrm{D}} / I_{\mathrm{G}}\right)$ is inversely proportional to the crystallization. The high $I_{\mathrm{D}} / I_{\mathrm{G}}$ value $(1.04$, compared with $\sim 0.1$ for fully graphitized carbon $)^{35,36}$ implies that the nitrogen doping induces more defects in this NCF, which can facilitate electron transport and trap more $\mathrm{Na}^{+}$ions during the electrochemical reactions..$^{27,37}$

Surface area and pore size are important factors for efficient $\mathrm{Na}^{+}$ion storage. The nitrogen adsorption isotherms of NCF (Fig. 2c) are a typical IV-type, indicative of a mesoporous structure. The NCF shows a high Brunauer-Emmett-Teller (BET) surface area of $623 \mathrm{~m}^{2} \mathrm{~g}^{-1}$, due to its porous hierarchical hollow structure. The pore size calculated using the BarrettJoyner-Halenda method (BJH) (Fig. 2d) varies from 4 to $58 \mathrm{~nm}$, demonstrating the presence of both micropores and mesopores. This high surface area and porous structure can effectively tolerate the volume changes during the continuous sodiation/de-sodiation. ${ }^{38}$ The mesopores also enable better contact between the electrode and the electrolyte, which is essential for good rate capability. ${ }^{17}$

The elemental analysis confirmed that content of element $\mathrm{N}$ in the NCF is $12.3 \mathrm{wt} \%$, higher than the previously reported N-doped carbon materials for SIBs applications. ${ }^{27-29}$ The XPS spectra indicate the chemical states of the elements in NCF (Fig. 3). The C $1 \mathrm{~s}$ band can be deconvoluted into three peaks. The peak at 284.4$284.6 \mathrm{eV}$ is ascribed to $\mathrm{sp}^{2}$ carbon, including $\mathrm{C}=\mathrm{C}$ and $\mathrm{C}=\mathrm{N}$ bonds. The higher energy peak at $286.0 \mathrm{eV}$ is associated with $\mathrm{sp}^{3}$ carbon, including $\mathrm{C}-\mathrm{C}$ and $\mathrm{C}-\mathrm{N}$ bonds. The $\mathrm{N} 1 \mathrm{~s}$ band can be deconvoluted into three peaks, pyridinic $\mathrm{N}$, pyrrolic $\mathrm{N}$, and quaternary N. Pyridinic $\mathrm{N}$ substitutes for a carbon atom in the sixmembered ring; pyrrolic $\mathrm{N}$ contributes two electrons to the fivemembered ring $\pi$ system; quaternary $\mathrm{N}$ substitutes a carbon

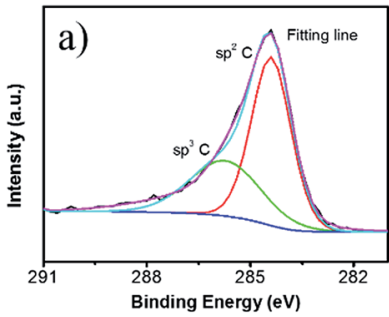

c) Content of different $\mathrm{N}$ types
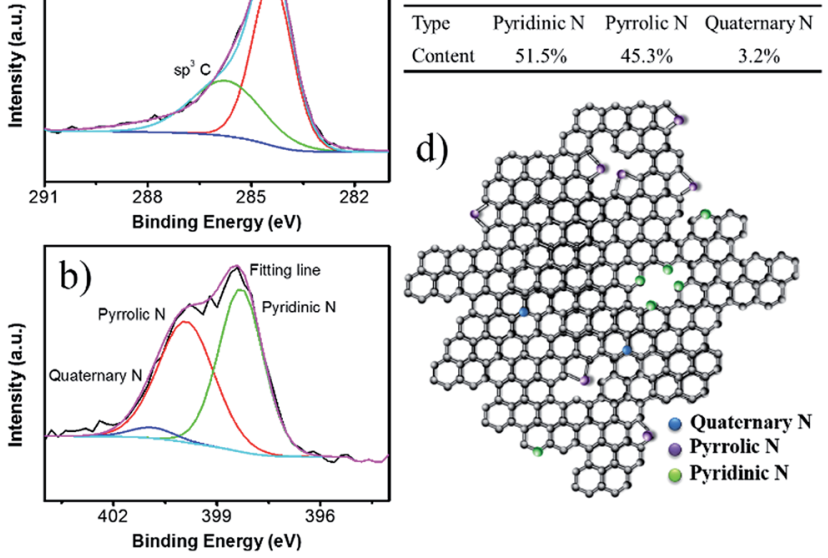

Fig. 3 High resolution XPS spectra for $C$ 1s (a) and $N$ 1s (b). The proportions of each $\mathrm{N}$ type (c), and a structural illustration of the carbon shell in NCF (d).

atom in the graphite lattice. The content of each type of $\mathrm{N}$ has been calculated based on the XPS fitting results (Fig. 3c), which is $51.5 \%$ pyridinic $\mathrm{N}, 45.3 \%$ pyrrolic $\mathrm{N}$, and $3.2 \%$ quaternary $\mathrm{N}$. Fig. 3d illustrates the $\mathrm{N}$ distribution and bonding states in the NCF. The high contents of pyridinic $\mathrm{N}$ and pyrrolic $\mathrm{N}$ create more defects and active sites for $\mathrm{Na}^{+}$insertion within the NCF, and therefore, facilitate ion transportation..$^{37,39}$

The sodium storage properties of NCF were characterized after been assembled into $2032 \mathrm{Na} / \mathrm{NCF}$ half cells. The initial four cyclic voltammograms (CVs) are presented in Fig. 4. The irreversible peaks around $0.01 \mathrm{~V}$ and $0.86 \mathrm{~V}$ could be ascribed to irreversible $\mathrm{Na}^{+}$traps and the formation of a solid-electrolyte interphase (SEI) film ${ }^{40,41}$ In the second cycle, the broad peak around $0.5 \mathrm{~V}$ could be attributed to sodium ion insertion. During the anodic process, the broad peak at $0.7 \mathrm{~V}$ is associated with the extraction of $\mathrm{Na}^{+}$from NCF. ${ }^{40}$ From the second cycle onward, the $\mathrm{CV}$ curves almost overlap with each other,

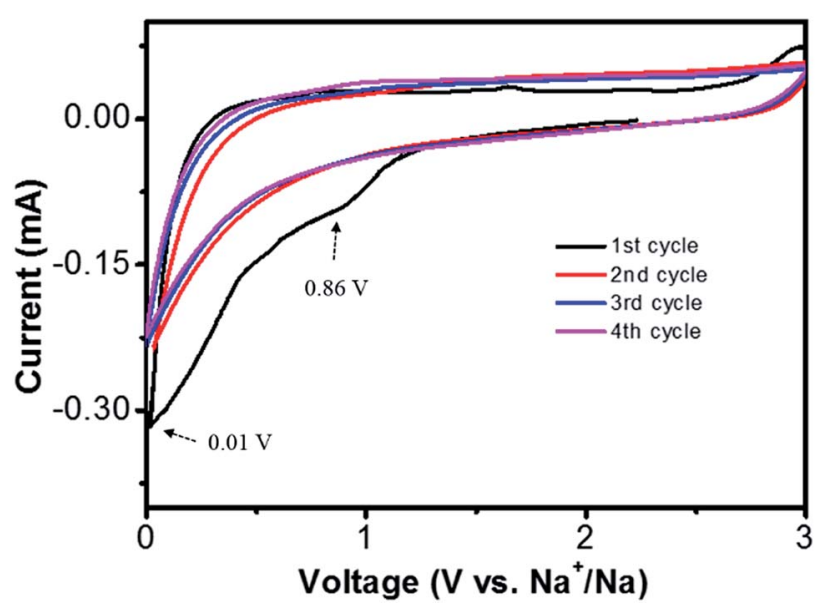

Fig. 4 Cyclic voltammograms of the $\mathrm{Na} / \mathrm{NCF}$ half cells at $0.5 \mathrm{mV} \mathrm{s}^{-1}$ scan rate, voltage $0.001-3 \mathrm{~V}$. 
indicating good cycle stability of the 3D NCF during sodiation/ desodiation process.

The discharge-charge experiments were performed at a current density of $100 \mathrm{~mA} \mathrm{~g}^{-1}$ (Fig. 5a). During the electrochemical process, the voltage profiles appear to be sloping lines without distinct plateaus, indicating the continuous insertion/deinsertion of $\mathrm{Na}^{+}$, which is consistent with the $\mathrm{CV}$ results. The first charge and discharge capacity of NCF is 327 and $864 \mathrm{~mA} \mathrm{~h} \mathrm{~g}{ }^{-1}$, corresponding to $37 \%$ coulombic efficiency (CE). This capacity loss is likely caused by the irreversible side reactions, such as formation of the SEI film, decomposition of the electrolyte, and the irreversible reaction between sodium and surface functional groups in NCF. ${ }^{40}$ After several cycles' stabilization, the NCF showed a stable charge and discharge capacity of 300 and 323 $\mathrm{mA} \mathrm{h} \mathrm{g}^{-1}$ at the $4^{\text {th }}$ cycle. This high first cycle reversible capacity (327 $\mathrm{mA} \mathrm{h} \mathrm{g}^{-1}$ ) and stable capacity ( $300 \mathrm{~mA} \mathrm{~h} \mathrm{~g}{ }^{-1}$ ) was higher than the theoretical capacity ( $279 \mathrm{~mA} \mathrm{~h} \mathrm{~g}^{-1}$ for carbon) and most reported results for $\mathrm{N}$-doped carbon materials, ${ }^{\mathbf{1 6}, 27-29}$ demonstrating the good electrochemical performance of the NCF.

Rate capability is another crucial factor for SIBs. The discharge-charge curves of the NCF at various current densities were carried out after stabilization (seen cycling performances of the NCF at different current densities in Fig. S1 in the ESI $\dagger$ ). The NCF only showed a slightly decreased capacity within the current density range of 100 to $2000 \mathrm{~mA} \mathrm{~g}^{-1}$ (Fig. 5b), e.g. a discharge capacity of $247,227,213$, and $201 \mathrm{~mA} \mathrm{~h} \mathrm{~g}{ }^{-1}$ obtained at 200, 400,600, and $800 \mathrm{~mA} \mathrm{~g}^{-1}$, respectively. The NCF can still deliver a high capacity of $175 \mathrm{~mA} \mathrm{~h} \mathrm{~g}^{-1}$, even at a high current density of $2000 \mathrm{~mA} \mathrm{~g}^{-1}$, corresponding to $64 \%$ capacity retention. Such excellent rate capability is rarely reported for carbon-based electrode in SIBs. ${ }^{\mathbf{1 1 , 2 9 , 4 2 - 4 4}}$ Importantly, when the current density was returned to $100 \mathrm{~mA} \mathrm{~g}^{-1}$, its capacity was

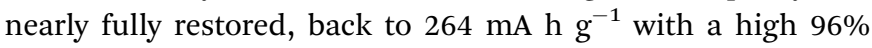
capacity retention. This clearly indicates the good integrity of our NCF electrode.
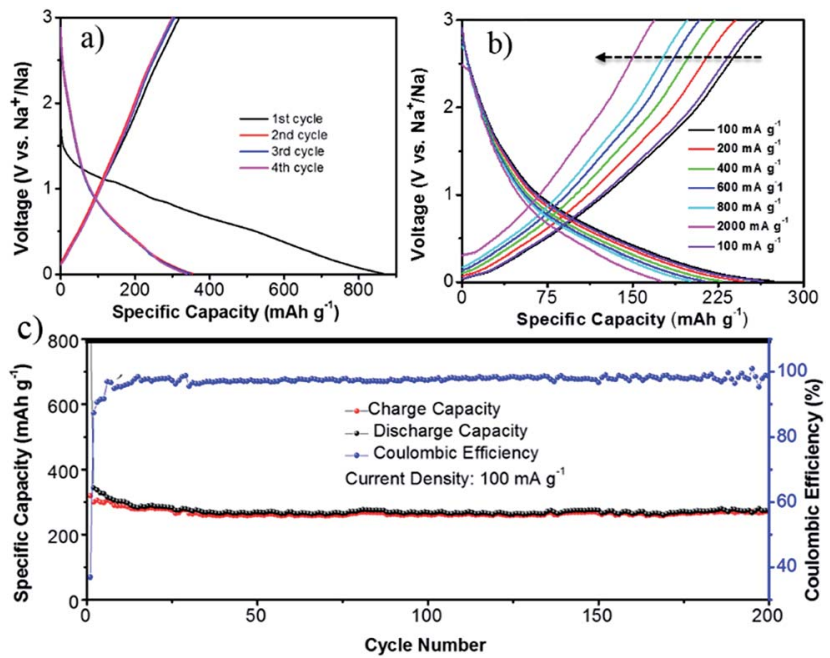

Fig. 5 Sodium storage performance of the NCF: discharge-charge profiles for the first 4 cycles at a current density of $100 \mathrm{~mA} \mathrm{~g}^{-1}$ (a); rate capability at various current densities (100-2000 $\mathrm{mA} \mathrm{g}^{-1}$ ) (b); and cycling performance (c).
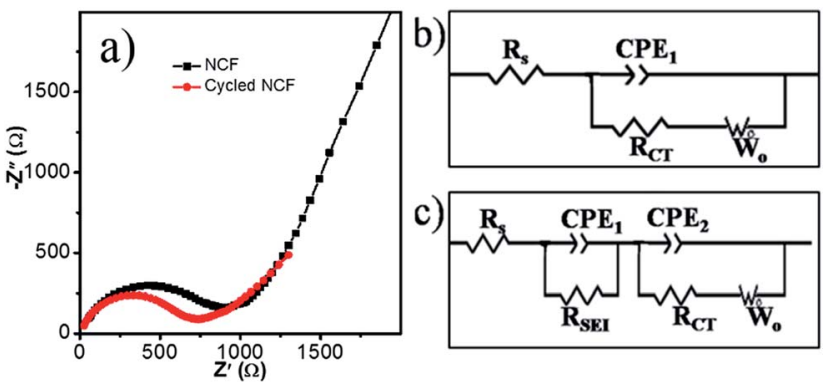

Fig. 6 Nyquist plots of the Na/NCF half cells in different states (a), the corresponding equivalent circuits for an as-fabricated half-cell (b) and for the half-cell after five charge/discharge cycles (c).

The long-life cycling stability of the NCF is shown in Fig. 5c. From the $12^{\text {th }}$ cycle onwards, the CE of NCF stays above $97 \%$. Even after 200 cycles of sodiation/de-sodiation, the electrode still exhibited a high capacity of $274 \mathrm{~mA} \mathrm{~h} \mathrm{~g}{ }^{-1}$ (86\% capacity retention), outperforming other reports. ${ }^{12,45,46}$ SEM images of the cycled NCF was given in Fig. S2, $\dagger$ which showed a certain degree of aggregation, but the polyhedral outline of NCF was well maintained, which still composed of numerous nanosubunits, this together with the electrochemical results demonstrated the good integrity of the NCF.

The good rate capability can be supported by the results from electrochemical impedance spectroscopy (EIS, Fig. 6). The semicircle and sloping line in the EIS curves are related to the resistance and Warburg impedance, respectively. To better explain the charge-transfer resistance during the cycling, equivalent circuits were used to fit these EIS plots. The components $R_{\mathrm{s}}, R_{\mathrm{ct}}, \mathrm{CPE}$, and $W_{\mathrm{o}}$ stand for the electrolyte resistance, charge-transfer resistance, constant phase element, and Warburg impedance, respectively. After five cycles, the formation of SEI film resulting a new resistance $R_{\mathrm{SEI}}$, therefore, the equivalent circuit of the cycled cells is different (Fig. 6c). The fitting results show that the $R_{\mathrm{S}}$ for the asassembled cell and the cell after 5 cycles is similar, 12 and $10 \Omega$, respectively. $R_{\mathrm{SEI}}$ in the cycled cells is $26 \Omega$. $R_{\mathrm{ct}}$ for the asassembled cell and the cell after 5 cycles is 730 and $670 \Omega$, respectively, which is lower than for graphene $(839.8 \Omega)$, and $\mathrm{N}$ doped graphene $(744.8 \Omega){ }^{47}$ The decreased $R_{\mathrm{ct}}$ indicated better electron transfer and therefore, better rate capability.

\section{Conclusions}

In summary, a 3D nitrogen-doped carbon framework with a high nitrogen content of $12.3 \mathrm{wt} \%$ was obtained via a facile two-step method (calcination and etching) using a ZIF-67 as precursor. The 3D NCF consists of numerous hollow spheres (3$5 \mathrm{~nm}$ in size), has a high surface area $\left(632 \mathrm{~m}^{2} \mathrm{~g}^{-1}\right)$, and is highly porous. The hollow sphere subunits in NCF can tolerate the volume changes during electrochemical cycling, resulting in improved cycling stability. The decreased $R_{\mathrm{ct}}$ and defect-rich structure caused by the $\mathrm{N}$-doping all contribute to the good electrochemical performance of NCF, such as the high reversible capacity, good cycling stability (86\% capacity retention after 200 cycles at $100 \mathrm{~mA} \mathrm{~g}^{-1}$ ), and exceptional excellent rate capability (175 $\mathrm{mA} \mathrm{h} \mathrm{g}^{-1}$ at $2000 \mathrm{~mA} \mathrm{~g}^{-1}$ current density). 


\section{Acknowledgements}

This work was supported by the National Science Foundation of China (NSFC) (51471089), the Ministry of Education (MOE) (IRT13R30), the 111 Project (B12015), and the Priority Academic Program Development Fund of Jiangsu Higher Education Institutions. The authors would like to thank the Australian National Fabrication Facility-Materials node (ANFF) for equipment use.

\section{Notes and references}

1 Y. Wang, Z. G. Huang and Y. J. Wang, J. Mater. Chem. A, 2015, 3, 21314-21320.

2 M. S. Whittingham, Chem. Rev., 2004, 104, 4271-4301.

3 J. M. Tarascon and M. Armand, Nature, 2001, 414, 359-367. 4 M. Sawicki and L. L. Shaw, RSC Adv., 2015, 5, 53129-53154. 5 Y. Wang, C. Y. Wang, Y. J. Wang, H. K. Liu and Z. G. Huang, J. Mater. Chem. A, 2016, 4, 5428-5435.

6 Y. Fu, Q. Wei, X. Wang, G. Zhang, H. Shu, X. Yang, A. C. Tavares and S. Sun, RSC Adv., 2016, 6, 16624-16633.

7 B. Nageswara Rao, P. Ramesh Kumar, O. Padmaraj, M. Venkateswarlu and N. Satyanarayana, RSC Adv., 2015, 5, 34761-34768.

8 J. P. Huang, D. D. Yuan, H. Z. Zhang, Y. L. Cao, G. R. Li, H. X. Yang and X. P. Gao, RSC Adv., 2013, 3, 12593-12597.

9 K. Nobuhara, H. Nakayama, M. Nose, S. Nakanishi and H. Iba, J. Power Sources, 2013, 243, 585-587.

10 K. Hyungsub, K. Haegyeom, D. Zhang, L. Myeong Hwan, L. Kyungmi, Y. Gabin and K. Kisuk, Adv. Energy Mater., 2016, 6, 1600943.

11 Y. Cao, L. Xiao, M. L. Sushko, W. Wang, B. Schwenzer, J. Xiao, Z. Nie, L. V. Saraf, Z. Yang and J. Liu, Nano Lett., 2012, 12, 3783-3787.

12 Y. Li, S. Xu, X. Wu, J. Yu, Y. Wang, Y.-S. Hu, H. Li, L. Chen and X. Huang, J. Mater. Chem. A, 2015, 3, 71-77.

13 Q. Wei, Y. Fu, G. Zhang, Y. Wang, X. Wang, M. Mohamedi and S. Sun, RSC Adv., 2016, 6, 84149-84154.

14 H. Liu, M. Jia, M. Wang, R. Chen, N. Sun, Q. Zhu, F. Wu and B. Xu, RSC Adv., 2016, 6, 78235-78240.

15 D. Qin, F. Zhang, S. Dong, Y. Zhao, G. Xu and X. Zhang, RSC Adv., 2016, 6, 106218-106224.

16 K. L. Zhang, X. N. Li, J. W. Liang, Y. C. Zhu, L. Hu, Q. S. Cheng, C. Guo, N. Lin and Y. T. Qian, Electrochim. Acta, 2015, 155, 174-182.

17 K. Tang, L. J. Fu, R. J. White, L. H. Yu, M. M. Titirici, M. Antonietti and J. Maier, Adv. Energy Mater., 2012, 2, 873-877.

18 N. R. Kim, Y. S. Yun, M. Y. Song, S. J. Hong, M. Kang, C. Leal, Y. W. Park and H. J. Jin, ACS Appl. Mater. Interfaces, 2016, 8, 3175-3181.

19 J. Ding, H. L. Wang, Z. Li, A. Kohandehghan, K. Cui, Z. W. Xu, B. Zahiri, X. H. Tan, E. M. Lotfabad, B. C. Olsen and D. Mitlin, ACS Nano, 2013, 7, 11004-11015.

20 J. Jin, S. J. Yu, Z. Q. Shi, C. Y. Wang and C. B. Chong, J. Power Sources, 2014, 272, 800-807.
21 R. Boyang, W. Jun, S. Dongqi, X. Yanfei, C. shulei, L. Huakun and W. Jiazhao, J. Mater. Chem. A, 2015, 3, 19011-19017.

22 Y. Jianchuan, Z. Jun, T. Zhaowu, Z. Ming-sen and D. QuanFeng, J. Mater. Chem. A, 2016, 4, 13223-13227.

23 J. Zhang, Z. Zhang and X. Zhao, RSC Adv., 2015, 5, 104822104828.

24 Z. Wang, Y. Li and X.-J. Lv, RSC Adv., 2014, 4, 62673-62677. 25 S. Vadahanambi, H.-H. Chun, K. H. Jung and H. Park, RSC Adv., 2016, 6, 38112-38116.

26 Y. Wang, C. Wang, Y. Wang, H. Liu and Z. Huang, ACS Appl. Mater. Interfaces, 2016, 8, 18860-18866.

27 Y. Wen, B. Wang, B. Luo and L. Wang, Eur. J. Inorg. Chem., 2016, 2051-2055.

28 Z. Wang, L. Qie, L. Yuan, W. Zhang, X. Hu and Y. Huang, Carbon, 2013, 55, 328-334.

29 L. Fu, K. Tang, K. Song, P. A. van Aken, Y. Yu and J. Maier, Nanoscale, 2014, 6, 1384-1389.

30 D. Wei, Y. Liu, Y. Wang, H. Zhang, L. Huang and G. Yu, Nano Lett., 2009, 9, 1752-1758.

31 Z.-H. Sheng, L. Shao, J.-J. Chen, W.-J. Bao, F.-B. Wang and X.-H. Xia, ACS Nano, 2011, 5, 4350-4358.

32 J. Zhou, N. Lin, W. l. Cai, C. Guo, K. Zhang, J. Zhou, Y. Zhu and Y. Qian, Electrochim. Acta, 2016, 218, 243-251.

33 Y.-J. Li, J.-M. Fan, M.-S. Zheng and Q.-F. Dong, Energy Environ. Sci., 2016, 9, 1998-2004.

34 Y. Wang, B. Wang, F. Xiao, Z. Huang, Y. Wang, C. Richardson, Z. Chen, L. Jiao and H. Yuan, J. Power Sources, 2015, 298, 203-208.

35 Y. Wang, C. An, Y. Wang, Y. Huang, C. Chen, L. Jiao and H. Yuan, J. Mater. Chem. A, 2014, 2, 16285-16291.

36 C. An, Y. Wang, Y. Xu, Y. Wang, Y. Huang, L. Jiao and H. Yuan, ACS Appl. Mater. Interfaces, 2014, 6, 3863-3869.

37 Y. C. Liu, N. Zhang, C. M. Yu, L. F. Jiao and J. Chen, Nano Lett., 2016, 16, 3321-3328.

38 I. Elizabeth, B. P. Singh, S. Trikha and S. Gopukumar, J. Power Sources, 2016, 329, 412-421.

39 Z. Zhu, S. Wang, J. Du, Q. Jin, T. Zhang, F. Cheng and J. Chen, Nano Lett., 2014, 14, 153-157.

40 H. Hou, C. E. Banks, M. Jing, Y. Zhang and X. Ji, Adv. Mater., 2015, 27, 7861-7866.

41 Y. Li, Y.-S. Hu, M.-M. Titirici, L. Chen and X. Huang, Adv. Energy Mater., 2016, 6, 1600659.

42 Z. Zhang, J. Zhang, X. Zhao and F. Yang, Carbon, 2015, 95, 552-559.

43 S. Komaba, W. Murata, T. Ishikawa, N. Yabuuchi, T. Ozeki, T. Nakayama, A. Ogata, K. Gotoh and K. Fujiwara, Adv. Funct. Mater., 2011, 21, 3859-3867.

44 J. Ding, H. Wang, Z. Li, A. Kohandehghan, K. Cui, Z. Xu, B. Zahiri, X. Tan, E. M. Lotfabad, B. C. Olsen and D. Mitlin, ACS Nano, 2013, 7, 11004-11015.

45 W. Li, L. Zeng, Z. Yang, L. Gu, J. Wang, X. Liu, J. Cheng and Y. Yu, Nanoscale, 2014, 6, 693-698.

46 H.-g. Wang, Z. Wu, F.-l. Meng, D.-l. Ma, X.-l. Huang, L.-m. Wang and X.-b. Zhang, ChemSusChem, 2013, 6, 56-60.

47 J. T. Xu, M. Wang, N. P. Wickramaratne, M. Jaroniec, S. X. Dou and L. M. Dai, Adv. Mater., 2015, 27, 2042-2048. 